\title{
Glomerular Hyperfiltration With Hyperglycemia in the Spontaneously Diabetic Torii (SDT) Fatty Rat, an Obese Type 2 Diabetic Model
}

\author{
Ryuhei SANO $^{1}$, Yukihito ISHII ${ }^{1}$, Masao YAMANAKA ${ }^{1}$, Yuzo YASUI ${ }^{2}$, Yusuke \\ KEMMOCHI $^{2}$, Fuko KUROKI ${ }^{3}$, Miki SUGIMOTO ${ }^{3}$, Sumiaki FUKUDA ${ }^{1}$, Tomohiko \\ SASASE ${ }^{1}$, Katsuhiro MIYAJIMA ${ }^{4}$, Dai NAKAE ${ }^{4}$, Takeshi OHTA ${ }^{3}$ \\ ${ }^{1}$ Biological/Pharmacological Research Laboratories, Central Pharmaceutical Research Institute, \\ Japan Tobacco Inc., Takatsuki, Osaka, Japan, ${ }^{2}$ Toxicology Research Laboratories, Central \\ Pharmaceutical Research Institute, Japan Tobacco Inc., Yokohama, Japan, ${ }^{3}$ Laboratory of Animal \\ Physiology and Functional Anatomy, Graduate School of Agriculture, Kyoto University, Kyoto, \\ Japan, ${ }^{4}$ Department of Nutritional Science and Food Safety, Faculty of Applied Biosciences, Tokyo \\ University of Agriculture, Tokyo, Japan
}

Received June 18, 2020

Accepted November 18, 2020

Epub Ahead of Print January 14, 2021

\section{Summary}

Glomerular hyperfiltration is observed in an early stage of kidney diseases including diabetic nephropathy. A better understanding of pathophysiological changes in glomerular hyperfiltration is essential for development of new therapies to prevent kidney disease progression. In this study, we investigated glomerular changes including glomerular filtration rate (GFR) and glomerular size in the Spontaneously Diabetic Torii (SDT) fatty rat, an obese type 2 diabetic model, and we also evaluated pharmacological effects of the sodium glucose cotransporter 2 inhibitor dapagliflozin on the renal lesions. Dapagliflozin was administered to SDT fatty rats from 5 to 17 weeks of age. Blood and urinary biochemical parameters were periodically measured. GFR was determined by transdermal GFR monitor at 16 weeks of age and histopathological analysis was performed at 17 weeks of age. SDT fatty rat developed severe hyperglycemia and exhibited pathophysiological abnormalities in the kidney, such as an increased GFR, glomerular hypertrophy and tissue lesions. Dapagliflozin achieved good glycemic control during the experimental period, inhibited the increase in GFR, and improved histopathological abnormalities in tubules. These results suggest that the SDT fatty rat is a useful model for analyzing the pathogenesis of diabetic nephropathy during its early stage and dapagliflozin improves not only hyperglycemia but also glomerular hyperfiltration and tubule lesions in SDT fatty rat.

\section{Key words}

Diabetes • GFR • Nephropathy • SDT fatty rats

\section{Corresponding author}

Y. Ishii, Biological/Pharmacological Research Laboratories, Central Pharmaceutical Research Institute, Japan Tobacco Inc., 1-1 Murasaki-cho, Takatsuki, Osaka 569-1125, Japan. E-mail: yukihito.ishii@jt.com

\section{Introduction}

Diabetic nephropathy or diabetic kidney disease is the most common cause of chronic kidney disease (CKD) and affects between $30 \%$ and $45 \%$ of patients with diabetes, leading to end-stage renal disease (Fouli and Gnudi 2019, Tuttle et al. 2014). Therapy for diabetic nephropathy is poor and the current treatment includes glycemic control with anti-diabetic drugs, inhibition of the renin-angiotensin aldosterone system, and lifestyle improvements (Fouli and Gnudi 2019, National Kidney 2012). Based on the current situation, prevention or early identification and treatment is important for management of diabetic nephropathy.

Early increase of GFR due to glomerular hyperfiltration plays a key role in pathogenesis and development of diabetic nephropathy (Ruggenenti et al.

PHYSIOLOGICAL RESEARCH • ISSN 1802-9973 (online) 
2012, Helal et al. 2012), and glomerular hyperfiltration is an early marker of renal damage in diabetes (Palatini 2012). In the EMPA-REG OUTCOME trial comparing 48 months of the sodium glucose cotransporter (SGLT) 2 inhibitor empagliflozin versus placebo in 7020 patients with type 2 diabetes, empagliflozin maintained the estimated glomerular filtration rate (eGFR) trajectory and stabilized renal function (Wanner et al. 2016, Tonneijck et al. 2017). In the DECLARE-TIMI 58 trial comparing 4.2 years of dapagliflozin versus placebo in 17160 patients with type 2 diabetes, dapagliflozin slowed eGFR decline and delayed renal disease progression (Mosenzon et al. 2019). Interestingly, empagliflozin and dapagliflozin suppressed the high level of eGFR during the early observational period, suggesting that the management of glomerular hyperfiltration is important for preventing the progression of diabetic nephropathy.

SDT fatty rat is a new obese type 2 diabetic rat that exhibits several diabetic complications (Matsui et al. 2008, Kemmochi et al. 2013, Katsuda et al. 2014) and was established by introducing the $f a$ allele of the Zucker fatty rat into the SDT rat genome (Masuyama et al. 2005). SDT rat, established as a non-obese model of type 2 diabetes (T2D) in 1997 (Shinohara et al. 2000), is originally an inbred strain of Sprague-Dawley rat. The male SDT fatty rat shows diabetic microangiopathies, such as peripheral neuropathy and macular edema-like ocular lesions (Maekawa et al. 2017, Motohashi et al. 2018, Murai et al. 2020), and the female SDT fatty rat manifests non-alcoholic steatohepatitis-like features (Ishii et al. 2015, Toriniwa et al. 2018).

The objective of this study is to characterize SDT fatty rat as a model of diabetic nephropathy. In this study, we investigated glomerular changes including GFR and glomerular size in male SDT fatty rats. As well, we investigated how SGLT2 inhibitor dapagliflozin affects glomerular changes and renal lesions in SDT fatty rats.

\section{Methods}

\section{Animals and compound}

This experiment was conducted in compliance with the Guidelines for Animal Experimentation at the Central Pharmaceutical Research Institute of Japan Tobacco. Male SDT fatty rats were purchased from CLEA Japan Inc. (Tokyo, Japan). Male Sprague-Dawley (SD) rats (CLEA Japan Inc., Japan) were used as a normal control rat. Rats were housed in suspended bracket cages and given a cholesterol-enriched powder diet (CRF-1 added $2 \%$ cholesterol, Oriental Yeast Co., Ltd. Tokyo, Japan) and water ad libitum in an environment controlled with respect to temperature $\left(23 \pm 3{ }^{\circ} \mathrm{C}\right)$, humidity $(55 \pm 15 \%)$, and illumination (a 12-h dark-light cycle). Dapagliflozin was purchased from (Combichem Inc., San Diego, California, United States). The drug, suspended in $0.5 \%$ methyl cellulose (MC) solution, was administered to SDT fatty rats orally by a stomach tube at a dose of $1 \mathrm{mg} / \mathrm{kg}$ from age 5 to 17 weeks.

\section{Biological parameters}

Food intake, body weight, blood biochemical parameters, such as plasma glucose, triglyceride (TG), total cholesterol (TC), and blood hemoglobin A1c (HbA1c) levels, and urinary biochemical parameters, such as glucose and protein, were evaluated every two weeks in rats from 5 to 17 weeks of age. Because there were multiple rats in each cage, food intake was calculated by dividing the total food intake per cage by the number of animals per cage. Blood samples were collected from the tail veins of rats. Urine samples were collected by placing the animals in metabolic cages. We selected $8 \mathrm{~h}$ as housing time in metabolic cage because housing in metabolic cage is likely stressful for SDT fatty rat and in our previous experiments, 24-hour housing in metabolic cage got worse the physiological condition of SDT fatty rats. Glucose, TG, TC, and HbA1c levels were measured using commercial kits (Roche Diagnostics Ltd., Basel, Switzerland) and an automatic analyzer (Hitachi Ltd., Tokyo, Japan). Urinary albumin excretion was measured with a commercially available kit (FUJIFILM Wako Pure Chemical Corporation, Osaka, Japan).

\section{Measurement of GFR}

GFR was determined by measuring the subcutaneous clearance of fluorescein isothiocyanate (FITC)-sinistrin with a transdermal GFR monitoring device (Medibeacon GmBH, Mannheim, Germany). A region on the back of each animal was depilated under light inhalation narcosis with an electrical shaver and depilatory cream, and the GFR monitor was attached to the depilated area by adhesive tape. Animals were lightly anesthetized and FITC-sinistrin was injected intravenously in the tail vein. The excretion kinetics of FITC-sinistrin was recorded at a sampling rate of 60 measurements per minute and an excitation time of $10 \mathrm{~ms}$ per measurement in conscious animals for $120 \mathrm{~min}$ 
as the subcutaneous fluorescence of FITC-sinistrin decayed. Elimination half-life (t1/2) was determined using an established 1-compartment model and then the t1/2 was converted into GFR using an empirical formula as previously described (Friedemann et al. 2016).

\section{Tissue sampling and histopathology}

Necropsy was performed at 17 weeks of age. All animals were sacrificed by exsanguination under isoflurane anesthesia. After the measurement of kidney weights, the kidneys were used for histopathological analysis. They were immediately fixed in $10 \%$ neutralbuffered formalin, paraffin-embedded using standard techniques, and thin-sectioned ( 3 to $5 \mu \mathrm{m}$ ). The sections were stained with hematoxylin and eosin (HE), examined histopathologically, and disease severity was graded from normal (-) to severe $(+++)$. To measure glomerular size, one section per rat was photographed under a light microscope (BX51, Olympus Corporation, Tokyo, Japan) using the $4 \mathrm{x}$ objective lens and analyzed using ImageJ software (Rasband WS, ImageJ, U. S. National Institutes of Health, Bethesda, Maryland, USA, https://imagej.nih.gov/ij/, 1997-2018.) as follows. The whole image of each section was stitched together by the Stitching plugin in ImageJ software (Preibisch et al. 2009) and unbiased counting frames with area sampling fraction of $30 \%$ and $2 \mathrm{~mm}$ intervals were superimposed using the Unbiased_Frames macro. The size of more than 50 glomeruli was measured in each animal with reference to the other reports (Malatiali et al. 2008, Kasiske et al. 1991). The profile of the glomeruli in the counting areas were traced manually using the Polygon tool. The best fit ellipse was determined for each glomerulus and lengths of the major axis and the minor axis were measured.

\section{Statistical analysis}

The biological parameter results are expressed as mean \pm standard deviation. Statistical evaluation of the difference between mean values was performed using an F-test, followed by a Student $t$-test or Aspin-Welch test. Differences were considered significant at $\mathrm{p}<0.05$.

\section{Results}

SDT fatty rat control group showed hyperphagia, and the food intakes in the dapagliflozin-treatment group did not significantly change as compared with those in the SDT fatty rat control group (Fig. 1A). Body weight increased in SDT fatty rat control group as compared with SD rat group from 5 to 9 weeks of age, but it decreased in SDT fatty rat control group after 1 weeks of age, as compared with SD rat group. The body weight increased in the dapagliflozin-treatment group as compared with the SDT fatty rat control group (Fig. 1B). SDT fatty rat control group showed significantly high levels of plasma glucose and HbA1c, as compared with SD rat group, and the dapagliflozin-treatment group showed significant improvement of hyperglycemia during the experimental period (Fig. 1C, D). Plasma TG levels in SDT fatty rat control group reached the peak at 7 weeks of age, and significantly increased from 7 to 13 weeks of age, compared with those in SD rat group. Plasma TG levels in the dapagliflozin-treatment group also reached the peak at 7 weeks of age to the same extent as SDT fatty rat control group, and afterwards remained at significantly higher levels than those in the SDT fatty rat control group. (Fig. 1E). Compared with SD rat group, SDT fatty rat control group showed significantly high levels of plasma TC, but the plasma TClevels in the dapagliflozin-treatment group remained unchanged relative to those in the SDT fatty rat control group (Fig. 1F).

Urinary glucose and albumin levels were significantly elevated in SDT fatty rat control group as compared with SD rat group during the experimental period. Dapagliflozin significantly suppressed the elevation in urinary glucose levels, but it did not suppress the elevation in urinary albumin levels (Fig. 2A, B).

The SDT fatty rat control group had significantly increased GFR as compared with that in the SD rat group, and dapagliflozin significantly suppressed the increase in GFR (SD rat group; $0.64 \pm 0.11 \mathrm{ml} / \mathrm{min} / 100 \mathrm{~g}$ body weight, SDT fatty rat control group; $0.88 \pm 0.11 \mathrm{ml} / \mathrm{min} / 100 \mathrm{~g}$ body weight, dapagliflozintreatment group; $0.68 \pm 0.08 \mathrm{ml} / \mathrm{min} / 100 \mathrm{~g}$ body weight) (Fig. 3A).

The SDT fatty rat control group had significantly increased glomerular size as compared with that in the SD rat group, and dapagliflozin did not suppress glomerular hypertrophy (SD rat group; $8924.0 \pm 1156.4 \mu \mathrm{m}^{2}$, SDT fatty rat control group; $14041.0 \pm 505.2 \mu \mathrm{m}^{2}, \quad$ dapagliflozin-treatment group; 12858.1 $\pm 1372.6 \mu \mathrm{m}^{2}$ ) (Fig. 3B).

Absolute kidney weight in the SDT fatty rat control group was significantly increased as compared with that in the SD rat group, and comparable between the dapagliflozin-treatment group and SDT fatty rat control group (SD rat group; $3.69 \pm 0.16 \mathrm{~g}$, SDT fatty rat control group; $5.16 \pm 0.61 \mathrm{~g}$, dapagliflozin-treatment 

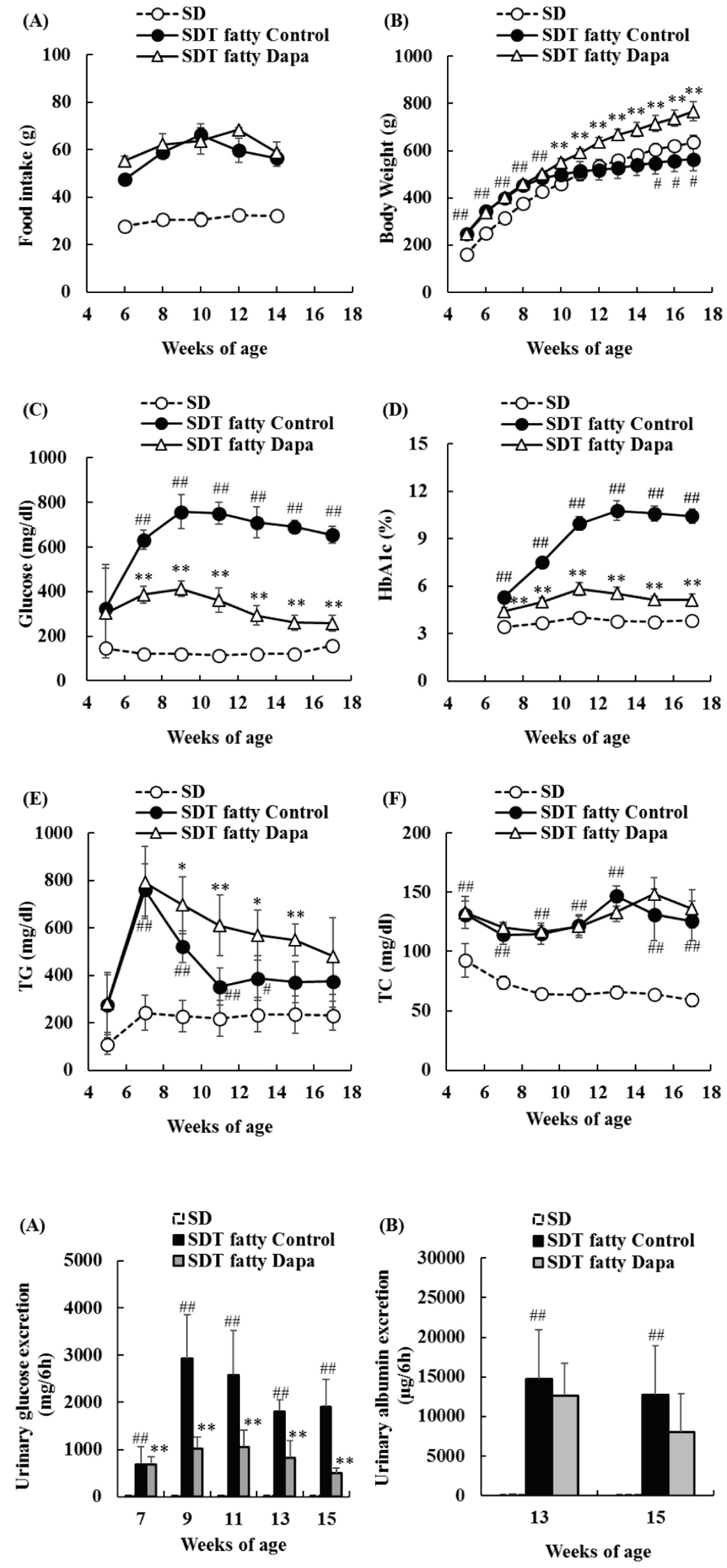

Fig. 1. Changes in food intake, body weight, and blood biochemistry parameters in SD, SDT fatty Control, and SDT fatty Dapagliflozin (Dapa) groups. (A): Food intake; (B): Body weight; (C): Glucose; (D): Glycated hemoglobin A1C (HbA1C); (E): Triglyceride (TG); (F): Total Cholesterol (TC). Data represent means \pm standard deviation $(n=6)$. ${ }^{\#} p<0.05, \quad \# p<0.01 ; \quad$ significantly different from the SD group. $* p<0.05$, $* * p<0.01$; significantly different from the SDT fatty Control group.
Fig. 2. Changes in urinary glucose $(\mathbf{A})$ and albumin (B) levels in SD, SDT fatty Control, and SDT fatty Dapagliflozin (Dapa) groups. Data represent means + standard deviation $(n=6)$. \#\# $p<0.01$; significantly different from the SD group. $* * p<0.01$; significantly different from the SDT fatty Control group. 
(A)


(B)

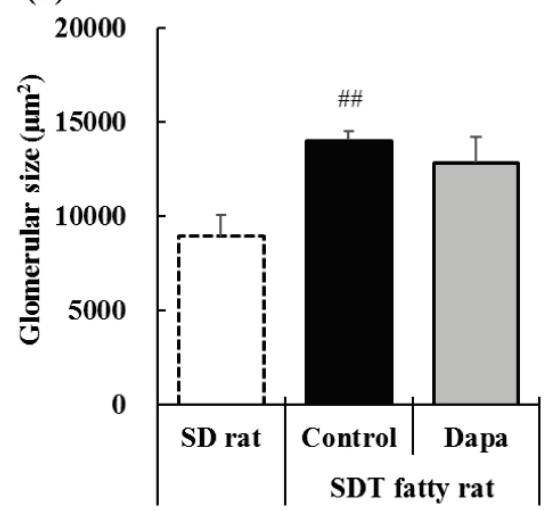

Fig. 3. Changes in glomerular filtration rate (GFR) (A) at 16 weeks of age, glomerular size (B), and kidney weight (C) at 17 weeks of age in SD, SDT fatty Control, and SDT fatty Dapagliflozin (Dapa) groups. Data represent means + standard deviation (Kidney weight; $n=6$ ). \# $p<0.05$, \#\# $p<0.01 ; \quad$ significantly different from the SD group. $* p<0.05$, $* * p<0.01$; significantly different from the SDT fatty Control group. group; $5.06 \pm 0.31 \mathrm{~g}$ ) (Fig. 3C). Relative kidney weight in the SDT fatty rat control group was significantly increased as compared with that in the SD rat group, but significantly decreased in the dapagliflozin-treatment group as compared with that in the SDT fatty rat control group (SD rat group; $5.79 \pm 0.14 \mathrm{mg} / \mathrm{g}$, SDT fatty rat control group; $9.15 \pm 0.71 \mathrm{mg} / \mathrm{g}$, dapagliflozin-treatment group; $6.60 \pm 0.27 \mathrm{mg} / \mathrm{g}$ ) (Fig. 3C).

In histopathological analysis, SDT fatty rats showed an increase in glomerular mesangial matrix, tubular lesions, such as epithelium flattening and elongation (epithelial degeneration), dilatation, hyaline cast formation, Armanni-Ebstein lesions, and mineralization, and interstitial lesions including inflammatory cell infiltration (Table 1). Dapagliflozin improved the tubular abnormalities, such as epithelial degeneration, dilatation, and Armanni-Ebstein lesions (Table 1 and Fig. 4).

\section{Discussion}

In addition to albuminuria and proteinuria, glomerular hyperfiltration is a useful marker in predicting renal damage in diabetes and the risk for end stage renal disease (ESRD). On the other hand, the physiological role of glomerular hyperfiltration is uncertain. Glomerular hyperfiltration in diabetes precedes the onset of albuminuria (Tonneijck et al. 2017, Brenner et al. 1996). This suggests that glomerular hyperfiltration is an important phenomenon associated with the progression of diabetic nephropathy, especially in the early stage.

SDT fatty rat is a new model of type 2 diabetes showing overt obesity, hyperglycemia and hyperlipidemia. Compared to other obese type 2 diabetic rats (e.g. Otsuka Long-Evans Tokushima fatty, Wistar fatty and Zucker diabetic fatty), SDT fatty rat develops diabetes and diabetes-associated complications at younger age (Katsuda et al. 2014). SDT fatty rats reportedly exhibit glomerular sclerosis and interstitial lesions after 24 or 31 weeks of age (Matsui et al. 2008). In this study, we used relatively young SDT fatty rats (5 to 17 weeks of age) and investigated glomerular changes, such as GFR and glomerular size to focus on the early stage of diabetic nephropathy. Around this age, SDT fatty rats reportedly exhibit slightly-to-moderate tubule lesions and normal-to-slight glomeruli lesions (Matsui et al. 2008). Therefore, we regarded that SDT fatty rats we used in this study was in the early state of diabetic nephropathy. 
Table 1. Histopathological findings in kidneys from 3 groups.

\begin{tabular}{|c|c|c|c|c|c|c|c|c|c|c|c|c|c|c|c|c|c|c|c|}
\hline \multirow{3}{*}{$\frac{\text { Organ }}{\text { Findings }}$} & \multirow{2}{*}{\multicolumn{7}{|c|}{ SD rat }} & \multicolumn{12}{|c|}{ SDT fatty rat } \\
\hline & & & & & & & & \multicolumn{6}{|c|}{ Control } & \multicolumn{6}{|c|}{ Dapagliflozin 1 mg/kg } \\
\hline & $\begin{array}{l}\text { Animal } \\
\text { number }\end{array}$ & 1 & 2 & 3 & 4 & 5 & 6 & 7 & 8 & 9 & 10 & 11 & 12 & 13 & 14 & 15 & 16 & 17 & 18 \\
\hline \multicolumn{20}{|l|}{$\underline{\text { Glomerulus }}$} \\
\hline \multicolumn{19}{|l|}{$\underline{\text { Tubules }}$} & + \\
\hline Degeneration/regeneration & & - & - & - & - & - & - & $2+$ & $2+$ & $2+$ & $2+$ & $2+$ & + & + & \pm & $2+$ & + & \pm & $2+$ \\
\hline Dilatation & & - & - & - & - & - & - & $2+$ & $2+$ & $2+$ & $2+$ & $2+$ & + & + & + & $2+$ & + & + & + \\
\hline Hyaline cast & & - & - & - & - & - & - & + & + & \pm & + & + & \pm & \pm & + & + & \pm & \pm & + \\
\hline Armanni-Ebstein lesion & & - & - & - & - & - & - & - & + & + & + & + & \pm & - & - & - & - & - & - \\
\hline \multicolumn{19}{|l|}{ Interstitial } & + \\
\hline $\begin{array}{l}\text { Infiltration, inflammatory } \\
\text { cells }\end{array}$ & & - & - & - & - & - & - & \pm & \pm & \pm & + & + & - & \pm & \pm & + & \pm & \pm & \pm \\
\hline Fibrosis & & - & - & - & - & - & - & \pm & - & - & - & - & - & \pm & - & - & - & - & - \\
\hline
\end{tabular}

-: negative; \pm : very slight; +: slight; $2+$ : moderate; $3+$ : severe.

(A)

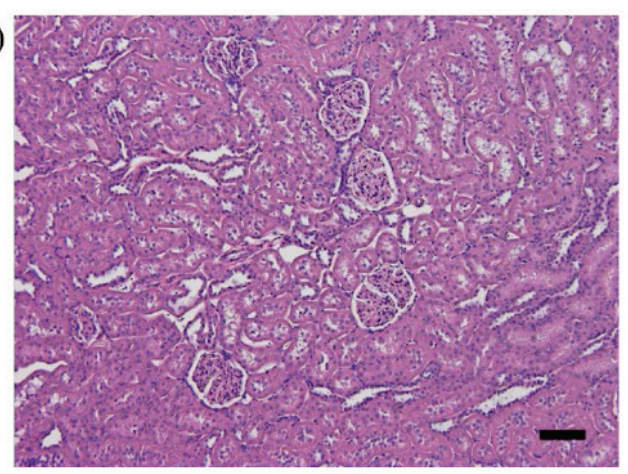

(B)

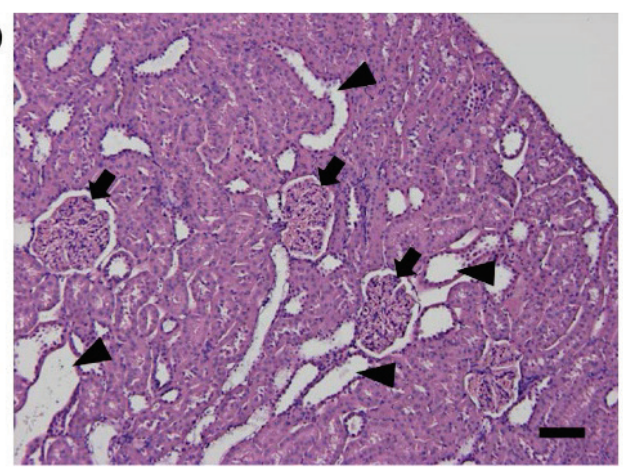

(C)

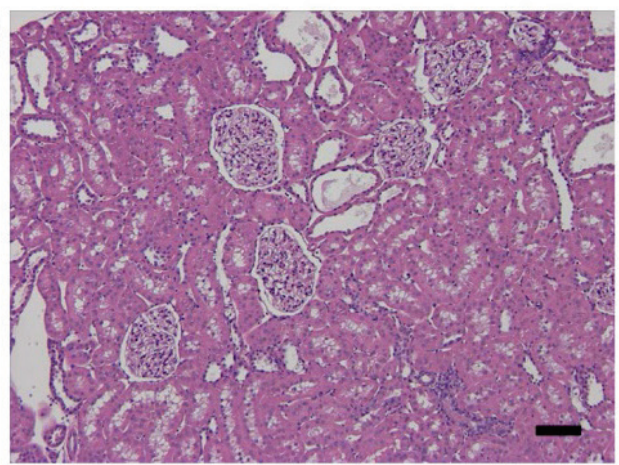

Fig. 4. Kidney histopathology at 17 weeks of age. (A): SD group; (B): SDT fatty Control group; (C): SDT fatty Dapagliflozin (Dapa) group. Bar $=100 \mu \mathrm{m}$. HE staining. The SDT fatty Control group showed histological changes, such as an increase of glomerular size (arrows) and tubular lesions including the dilation (arrow heads).

In this study, SDT fatty rats exhibited hyperphagia, hyperglycemia and hyperlipidemia from young age. SDT fatty rats gained weight until 10 weeks of age but hardly gained more weight from 11 weeks of age. We speculate that the suppression of weight gain is due to lack of insulin effect because SDT fatty rats exhibit severe insulin resistance and decreased insulin secretion (Masuyama et al. 2005, Katsuda et al. 2015). SDT fatty rats treated with dapagliflozin continued to gain weight during the experiment. Improvement of hyperglycemia by dapagliflozin is considered to influence general condition, leading to further increases in body weight. Plasma TG levels in the dapagliflozin-treatment group remained higher than those in the SDT fatty rat control group after 9 weeks of age. We speculate that this result was due to the increased lipogenesis by hyperinsulinemia. In insulin-resistant states, hyperinsulinemia increases hepatic de novo lipogenesis mediated by induction of SREBP expression, resulting in the increased hepatic TG production (Chirieac et al. 2004). In this study, SDT fatty rats exhibited hyperinsulinemia from 5 to 7 weeks of age, and afterwards their plasma insulin levels decreased to the same level as those in SD rat (data not shown). This is consistent with previous reports (Matsui et al. 2008, Kemmochi et al. 2018). On the other 
hand, plasma insulin levels in the dapagliflozin-treatment group remained higher than those in the SDT fatty rat control group even after 9 weeks of age (data not shown). From this, we speculate that the lasting hyperinsulinemia in the dapagliflozin-treatment group continued to induce hepatic lipogenesis, resulting that plasma TG levels remained higher than those in SDT fatty control group.

Urinary glucose excretion in dapagliflozintreatment group was lower than that in SDT fatty rat control group from 9 to 15 weeks of age. Given mechanism of SGLT2 inhibition, this result seems to be contradictory. However, this result can be explained by the fact that sustained reduction of blood glucose levels with dapagliflozin results in the significant decrease in the glucose filtered in glomerulus and subsequently leads to the decrease in urinary glucose excretion.

SDT fatty rats showed albuminuria and increase in GFR. Increased GFR indicates that glomerular hyperfiltration is present. The Increase in GFR due to glomerular hyperfiltration in SDT fatty rats corresponds to the early pathophysiological change observed in patients with diabetic nephropathy. Sustained hyperglycemia induces oxidative stress in the glomerular endothelial layer, and vascular permeability is accelerated leading to glomerular hyperfiltration (Kuwabara et al. 2010, Takenaka et al. 2011). Recent studies reported that dapagliflozin had no effect on GFR in SD rats (Zhang et al. 2016, Rajasekeran et al. 2018). In this study, dapagliflozin inhibited the increase in GFR in SDT fatty rats. Possible reason for this is the normalization of altered tubuloglomerular feedback induced by hyperglycemic conditions, resulting in the normalization of hyperglycema-induced glomerular hyperfiltration and higher intraglomerular pressure, which are well-known accelerators of kidney injury. In the EMPA-REG OUTCOME trial, empagliflozin suppressed the eGFR elevation and subsequently maintained the eGFR trajectory and stabilized renal function (Wanner et al. 2016, Tonneijck et al. 2017). In the future, it would be necessary to confirm that extended treatment with SGLT2 inhibitors maintains GFR and shows renal protective effect in SDT fatty rats.

Glomerular hypertrophy was also observed in SDT fatty rats, but it was not improved by dapagliflozin treatment. The reason for this is unclear. Factors other than improvement of hyperglycemia and glomerular hyperfiltration may be involved. For example, a neutralizing vascular endothelial growth factor (VEGF) antibody reportedly prevents glomerular hypertrophy in the Zucker diabetic fatty rat, a model of obese type 2 diabetes (Schrijvers et al. 2006), and the acceleration of vascular permeability is considered to relate to the pathogenesis of glomerular hypertrophy. Abnormal lipid metabolism also is risk factor for the progression of diabetic nephropathy (Russo et al. 2016). In this study, dapagliflozin treatment failed to reduce plasma TG and TC levels. On the other hand, ezetimibe, a cholesterollowering drug reportedly improved glomerular hypertrophy independent of glucose metabolism in diabetic mice (Tamura et al. 2012). Improvement of dyslipidemia might be needed to improve glomerular hypertrophy.

An increase in mesangial matrix and interstitial inflammation were observed in SDT fatty rats, but dapagliflozin did not improve them. Previous reports have demonstrated that dapagliflozin improved the increase in mesangial matrix and interstitial inflammation in models of diabetic nephropathy (Hatanaka et al. 2016, Tang et al. 2017). The reason for this discrepancy is unknown. However, lesion severity in glomerulus and interstitial in SDT fatty rats was slight in this study, and therefore it might have been difficult to detect improvement effects by dapagliflozin. Longer-term treatment of dapagliflozin may be necessary to improve them in SDT fatty rats.

Tubular lesions, such as epithelium flattening, dilatation, and Armanni-Ebstein lesions, were observed in SDT fatty rats, and the dapagliflozin improved those tubular lesions. This is consistent with previous reports with dapagliflozin and other SGLT2 inhibitor (Han et al. 2018, Takiyama et al. 2018).

In conclusion, SDT fatty rat developed severe hyperglycemia and exhibited pathophysiological abnormalities in the kidney, such as an increase in GFR, glomerular hypertrophy and tissue lesions. SGLT2 inhibitor dapagliflozin achieved good glycemic control, inhibited the increase in GFR and improved histopathological abnormalities in tubules. These results suggest that the SDT fatty rat is a useful model for analyzing the pathogenesis of diabetic nephropathy during its early stage and dapagliflozin improves not only hyperglycemia but also glomerular hyperfiltration and tubule lesions in SDT fatty rat.

\section{Conflict of Interest}

There is no conflict of interest. Sano, Ishii, Yamanaka, Yasui, Kemmochi, Fukuda and Sasase are employees of Japan Tobacco Inc. 


\section{Acknowledgements}

We thank JT Creative Service for long-term animal care.

\section{References}

BRENNER BM, LAWLER EV MACKENZIE HS: The hyperfiltration theory: a paradigm shift in nephrology. Kidney Int 49: 1774-1777, 1996. https://doi.org/10.1038/ki.1996.265

CHIRIEAC DV, COLLINS HL, CIANCI J, SPARKS JD, SPARKS CE: Altered triglyceride-rich lipoprotein production in Zucker diabetic fatty rats. Am J Physiol Endocrinol Metab 287: E42-E49, 2004. https://doi.org/10.1152/ajpendo.00297.2003

FOULI GE, GNUDI L: The future: Experimental therapies for renal disease in diabetes. Nephron 143: 3-7, 2019. https://doi.org/10.1159/000492825

FRIEDEMANN J, HEINRICH R, SHULHEVICH Y, RAEDLE M, WILLIAM-OLSSON L, PILL J, SCHOCKKUSCH D: Improved kinetic model for the transcutaneous measurement of glomerular filtration rate in experimental animals. Kidney Int 90: 1377-1385, 2016. https://doi.org/10.1016/j.kint.2016.07.024

HAN E, SHIN E, KIM G, LEE JY, LEE YH, LEE BW, KANG ES, CHA BS: Combining SGLT2 inhibition with a thiazolidinedione additively attenuate the very early phase of diabetic nephropathy progression in type 2 diabetes mellitus. Front Endocrinol (Lausanne) 9: 412, 2018. https://doi.org/10.3389/fendo.2018.00412

HATANAKA T, OGAWA D, TACHIBANA H, EGUCHI J, INOUE T, YAMADA H, TAKEI K, MAKINO H, WADA J: Inhibition of SGLT2 alleviates diabetic nephropathy by suppressing high glucose-induced oxidative stress in type 1 diabetic mice. Pharmacol Res Perspect 4: e00239, 2016. https://doi.org/10.1002/prp2.239

HELAL I, FICK-BROSNAHAN GM, REED-GITOMER B, SCHRIER RW: Glomerular hyperfiltration: definitions, mechanisms and clinical implications. Nat Rev Nephrol 8: 293-300, 2012. https://doi.org/10.1038/nrneph.2012.19

ISHII Y, MOTOHASHI Y, MURAMATSU M, KATSUDA Y, MIYAJIMA K, SASASE T, YAMADA T, MATSUI T, KUME S, OHTA T: Female spontaneously diabetic Torii fatty rats develop nonalcoholic steatohepatitis-like hepatic lesions. World J Gastroenterol 21: 9067-9078, 2015. https://doi.org/10.3748/wjg.v21.i30.9067

KASISKE BL, O'DONNELL MP, LEE H, KIM Y, KEANE WF: Impact of dietary fatty acid supplementation on renal injury in obese Zucker rats. Kidney Int 39: 1125-1134, 1991. https://doi.org/10.1038/ki.1991.143

KATSUDA Y, OHTA T, MIYAJIMA K, KEMMOCHI Y, SASASE T, TONG B, SHINOHARA M, YAMADA T: Diabetic complications in obese type 2 diabetic rat models. Exp Anim 63: 121-132, 2014. https://doi.org/10.1538/expanim.63.121

KATSUDA Y, SASASE T, TADAKI H, MERA Y, MOTOHASHI Y, KEMMOCHI Y, TOYODA K, KAKIMOTO K, KUME S, OHTA T: Contribution of hyperglycemia on diabetic complications in obese type 2 diabetic SDT fatty rats: effects of SGLT inhibitor phlorizin. Exp Anim 64: 161-169, 2015. https://doi.org/10.1538/expanim.14-0084

KEMMOCHI Y, FUKUI K, MAKI M, KIMURA S, ISHII Y, SASASE T, MIYAJIMA K, OHTA T: Metabolic disorders and diabetic complications in Spontaneously Diabetic Torii Lepr (fa) rat: A new obese type 2 diabetic model. J Diabetes Res 2013: 948257, 2013. https://doi.org/10.1155/2013/948257

KEMMOCHI Y, OHTA T, MOTOHASHI Y, KANESHIGE A, KATSUMI S, KAKIMOTO K, YASUI Y, ANAGAWA-NAKAMURA A, TOYODA K, TANIAI-RIYA E, TAKAHASHI A, SHODA T, YAMADA T: Pathophysiological analyses of skeletal muscle in obese type 2 diabetes SDT fatty rats. J Toxicol Pathol 31: 113-123, 2018. https://doi.org/10.1293/tox.2017-0064

KUWABARA A, SATOH M, TOMITA N, SASAKI T, KASHIHARA N: Deterioration of glomerular endothelial surface layer induced by oxidative stress is implicated in altered permeability of macromolecules in Zucker fatty rats. Diabetologia 53: 2056-2065, 2010. https://doi.org/10.1007/s00125-010-1810-0

MAEKAWA T, TADAKI H, SASASE T, MOTOHASHI Y, MIYAJIMA K, OHTA T, KUME S: Pathophysiological profiles of SDT fatty rats, a potential new diabetic peripheral neuropathy model. J Pharmacol Toxicol Methods 88: 160-166, 2017. https://doi.org/10.1016/j.vascn.2017.09.257

MALATIALI S, FRANCIS I, BARAC-NIETO M: Phlorizin prevents glomerular hyperfiltration but not hypertrophy in diabetic rats. Exp Diabetes Res 2008: 305403, 2008. https://doi.org/10.1155/2008/305403 
MASUYAMA T, KATSUDA Y, SHINOHARA M: A novel model of obesity-related diabetes: introgression of the Lepr(fa) allele of the Zucker fatty rat into nonobese Spontaneously Diabetic Torii (SDT) rats. Exp Anim 54: 13-20, 2005. https://doi.org/10.1538/expanim.54.13

MATSUI K, OHTA T, ODA T, SASASE T, UEDA N, MIYAJIMA K, MASUYAMA T, SHINOHARA M, MATSUSHITA M: Diabetes-associated complications in Spontaneously Diabetic Torii fatty rats. Exp Anim 57: 111-121, 2008. https://doi.org/10.1538/expanim.57.111

MOSENZON O, WIVIOTT SD, CAHN A, ROZENBERG A, YANUV I, GOODRICH EL, MURPHY SA, HEERSPINK HJL, ZELNIKER TA, DWYER JP, BHATT DL, LEITER LA, MCGUIRE DK, WILDING JPH, KATO ET, GAUSE-NILSSON IAM, FREDRIKSSON M, JOHANSSON PA, LANGKILDE AM, SABATINE MS, RAZ I: Effects of dapagliflozin on development and progression of kidney disease in patients with type 2 diabetes: an analysis from the DECLARE-TIMI 58 randomised trial. Lancet Diabetes Endocrinol 7: 606-617, 2019. https://doi.org/10.1016/S2213-8587(19)30180-9

MOTOHASHI Y, KEMMOCHI Y, MAEKAWA T, TADAKI H, SASASE T, TANAKA Y, KAKEHASHI A, YAMADA T, OHTA T: Diabetic macular edema-like ocular lesions in male Spontaneously Diabetic Torii fatty rats. Physiol Res 67: 423-432, 2018. https://doi.org/10.33549/physiolres.933709

MURAI Y, SASASE T, TADAKI H, HEITAKU S, IMAGAWA N, YAMADA T, OHTA T: Analysis of haemodynamics and angiogenic response to ischaemia in the obese type 2 diabetic model Spontaneously Diabetic Torii Lepr(fa) (SDT fatty) rats. Clin Exp Pharmacol Physiol 47: 583-590 2020. https://doi.org/10.1111/1440-1681.13239

NATIONAL KIDNEY FOUNDATION: KDOQI Clinical Practice Guideline for Diabetes and CKD: 2012 Update. Am J Kidney Dis 60: 850-886, 2012. https://doi.org/10.1053/j.ajkd.2012.07.005

PALATINI P: Glomerular hyperfiltration: a marker of early renal damage in pre-diabetes and pre-hypertension. Nephrol Dial Transplant 27: 1708-1714, 2012. https://doi.org/10.1093/ndt/gfs037

PREIBISCH S, SAALFELD S, TOMANCAK P: Globally optimal stitching of tiled 3D microscopic image acquisitions. Bioinformatics 25: 1463-1465, 2009. https://doi.org/10.1093/bioinformatics/btp184

RAJASEKERAN H, REICH HN, HLADUNEWICH MA, CATTRAN D, LOVSHIN JA, LYTVYN Y, BJORNSTAD P, LAI V, TSE J, CHAM L, MAJUMDER S, BOWSKILL BB, KABIR MG, ADVANI SL, GIBSON IW, SOOD MM, ADVANI A, CHERNEY DZI: Dapagliflozin in focal segmental glomerulosclerosis: a combined humanrodent pilot study. Am J Physiol Renal Physiol 314: F412-F422, 2018. https://doi.org/10.1152/ajprenal.00445.2017

RUGGENENTI P, PORRINI EL, GASPARI F, MOTTERLINI N, CANNATA A, CARRARA F, CELLA C, FERRARI S, STUCCHI N, PARVANOVA A, ILIEV I, DODESINI AR, TREVISAN R, BOSSI A, ZALETEL J, REMUZZI G, INVESTIGATORS GFRS: Glomerular hyperfiltration and renal disease progression in type 2 diabetes. Diabetes Care 35: 2061-2068, 2012. https://doi.org/10.2337/dc11-2189

RUSSO GT, DE COSMO S, VIAZZI F, PACILli A, CERIELlO A, GENOVESE S, GUIDA P, GIORDA C, CUCINOTTA D, PONTREMOLI R, FIORETTO P, GROUP AM-AS: Plasma triglycerides and HDL-C levels predict the development of diabetic kidney disease in subjects with type 2 diabetes: The AMD annals initiative. Diabetes Care 39: 2278-2287, 2016. https://doi.org/10.2337/dc16-1246

SCHRIJVERS BF, FLYVBJERG A, TILTON RG, LAMEIRE NH, DE VRIESE AS: A neutralizing VEGF antibody prevents glomerular hypertrophy in a model of obese type 2 diabetes, the Zucker diabetic fatty rat. Nephrol Dial Transplant 21: 324-329, 2006. https://doi.org/10.1093/ndt/gfi217

SHINOHARA M, MASUYAMA T, SHODA T, TAKAHASHI T, KATSUDA Y, KOMEDA K, KUROKI M, KAKEHASHI A, KANAZAWA Y: A new spontaneously diabetic non-obese Torii rat strain with severe ocular complications. Int J Exp Diabetes Res 1: 89-100, 2000. https://doi.org/10.1155/EDR.2000.89

TAKENAKA T, INOUE T, OKADA H, OHNO Y, MIYAZAKI T, CHASTON DJ, HILL CE, SUZUKI H: Altered gap junctional communication and renal haemodynamics in Zucker fatty rat model of type 2 diabetes. Diabetologia 54: 2192-2201, 2011. https://doi.org/10.1007/s00125-011-2175-8

TAKIYAMA Y, SERA T, NAKAMURA M, ISHIZEKI K, SAIJO Y, YANAGIMACHI T, MAEDA M, BESSHO R, TAKIYAMA T, KITSUNAI H, SAKAGAMI H, FUJISHIRO D, FUJITA Y, MAKINO Y, ABIKO A, HOSHINO M, UESUGI K, YAGI N, OTA T, HANEDA M: Impacts of diabetes and an SGLT2 inhibitor on the glomerular number and volume in $\mathrm{db} / \mathrm{db}$ Mice, as estimated by synchrotron radiation micro-CT at SPring8. EBioMedicine 36: 329-346, 2018. https://doi.org/10.1016/j.ebiom.2018.09.048 
TAMURA Y, MURAYAMA T, MINAMI M, MATSUBARA T, YOKODE M, ARAI H: Ezetimibe ameliorates early diabetic nephropathy in db/db mice. J Atheroscler Thromb 19: 608-618, 2012. https://doi.org/10.5551/jat.11312

TANG L, WU Y, TIAN M, SJOSTROM CD, JOHANSSON U, PENG XR, SMITH DM, HUANG Y: Dapagliflozin slows the progression of the renal and liver fibrosis associated with type 2 diabetes. Am J Physiol Endocrinol Metab 313: E563-E576, 2017. https://doi.org/10.1152/ajpendo.00086.2017

TONNEIJCK L, MUSKIET MH, SMITS MM, VAN BOMMEL EJ, HEERSPINK HJ, VAN RAALTE DH, JOLES JA: Glomerular hyperfiltration in diabetes: Mechanisms, clinical significance, and treatment. J Am Soc Nephrol 28: 1023-1039, 2017. https://doi.org/10.1681/ASN.2016060666

TORINIWA Y, MURAMATSU M, ISHII Y, RIYA E, MIYAJIMA K, OHSHIDA S, KITATANI K, TAKEKOSHI S, MATSUI T, KUME S, YAMADA T, OHTA T: Pathophysiological characteristics of non-alcoholic steatohepatitis-like changes in cholesterol-loaded type 2 diabetic rats. Physiol Res 67: 601-612, 2018. https://doi.org/10.33549/physiolres.933784

TUTTLE KR, BAKRIS GL, BILOUS RW, CHIANG JL, DE BOER IH, GOLDSTEIN-FUCHS J, HIRSCH IB, KALANTAR-ZADEH K, NARVA AS, NAVANEETHAN SD, NEUMILLER JJ, PATEL UD, RATNER RE, WHALEY-CONNELL AT, MOLITCH ME: Diabetic kidney disease: a report from an ADA Consensus Conference. Diabetes Care 37: 2864-2883, 2014. https://doi.org/10.2337/dc14-1296

WANNER C, INZUCCHI SE, LACHIN JM, FITCHETT D, VON EYNATTEN M, MATTHEUS M, JOHANSEN OE, WOERLE HJ, BROEDL UC, ZINMAN B, INVESTIGATORS E-RO: Empagliflozin and progression of kidney disease in type 2 diabetes. N Engl J Med 375: 323-334, 2016. https://doi.org/10.1056/NEJMoa1515920

ZHANG Y, THAI K, KEPECS DM, GILBERT RE: Sodium-glucose linked cotransporter-2 inhibition does not attenuate disease progression in the rat remnant kidney model of chronic kidney disease. PLoS One 11: e0144640, 2016. https://doi.org/10.1371/journal.pone.0144640 